Article

\title{
Extraction Optimization, Structural Characterization, and Anticoagulant Activity of Acidic Polysaccharides from Auricularia auricula-judae
}

\author{
Chun Bian ${ }^{1,2}$, Zhenyu Wang ${ }^{1, *}$ and John Shi ${ }^{1,3, *}$ \\ 1 School of Chemistry and Chemical Engineering, Harbin Institute of Technology, Harbin 150001, China; \\ ji3526183@126.com \\ 2 School of Food Engineering, Harbin University, Harbin 150086, China \\ 3 Agriculture and Agri-Food Canada Guelph Food Research Center, Guelph, ON N1G5C9, Canada \\ * Correspondence: WZY219001@163.com (Z.W.); johnshi2006@yahoo.ca (J.S.); Tel.: +86-1303-996-0001 (Z.W.)
}

Received: 12 January 2020; Accepted: 4 February 2020; Published: 6 February 2020

\begin{abstract}
To explore Auricularia auricula-judae polysaccharides (AAP) as natural anticoagulants for application in the functional food industry, ultrasound assisted extraction (UAE) was optimized for the extraction of AAP by using a response surface methodology (RSM). The maximum extraction yield of crude AAP $(14.74 \mathrm{mg} / \mathrm{g})$ was obtained at the optimized extraction parameters as follows: Extraction temperature $\left(74^{\circ} \mathrm{C}\right)$, extraction time $(27 \mathrm{~min})$, the ratio of liquid to raw material $(103 \mathrm{~mL} / \mathrm{g})$, and ultrasound power $(198 \mathrm{~W})$. Furthermore, the acidic AAP (aAAP) was precipitated with cetyltrimethylammonium bromide (CTAB) from crude AAP (cAAP). aAAP was further purified using ion exchange chromatography with a DEAE Purose 6 Fast Flow column to obtain aAAP-1. Additionally, according to the HPLC analysis, the aAAP-1 was mainly composed of mannose, glucuronic acid, glucose, galactose, and xylose, with a molar ratio of 80.63:9.88:2.25:1:31.13. Moreover, the results of the activated partial thromboplastin time (APTT), prothrombin time (PT), and thrombin time (TT) indicated aAAP-1 had anticoagulant activity, which was a synergic anticoagulant activity by the endogenous and exogenous pathway.
\end{abstract}

Keywords: corresponding surface optimization; ultrasound assisted extraction; chemical composition; anticoagulation in vitro

\section{Introduction}

A hypercoagulable state or thrombus can be induced by an imbalance between coagulation and anticoagulation or coagulation and fibrinolysis, which also leads to the instability of atherosclerosis plaque, thus inducing ischemic cardiovascular and cerebrovascular disease [1]. According to the World Health Organization (WHO), thrombosis-related cerebrovascular disease and stroke are the main factors of mortality worldwide, which are expected to cause almost 3.6 million deaths by 2030 [2]. Anticoagulants are widely used in the medicinal field for treating diseases like strokes and myocardial infarction [3]. Since the 1940s, heparin has been the predominant anticoagulant and antithrombotic drug [4]. However recently, it has been found that heparin has several side effects, such as bleeding, thrombocytopenia [5,6], hyperkalemia, and risk of infection with animal pathogens, due to its origin $[7,8]$. Hence, it is necessary to find a safe anticoagulant from a natural substitute for heparin. It has been reported that polysaccharides with anticoagulant and antithrombotic activity are not only from marine origins with a sulfated structure $[3,4,9]$ but also are from plants and edible fungi $[10,11]$.

A. auricula-judae is a kind of saprophyte that grows on deadwood sourced as either wild or cultivated and its subsidiary is the edible part. It is the main genus among edible macro fungi, and northeast 
China is the main production area [12]. A. auricula-judae is a species of food and medicine homology particularly used in traditional Asian medicine. A. auricula-judae is rich in proteins, fats, vitamins, and trace elements [13], besides, its polysaccharides (AAP) are the main functional component [14]. Many biological functions of AAP have been reported by previous studies, such as antioxidant activity [15,16], immunomodulatory activity [17], hypoglycemic or anti-diabetic properties [18], radio-protective properties [19], anti-cancer or anti-tumor properties [20,21], anti-bacterial [22] or anti-viral properties [23], and anti-hypercholesterolemic properties [24]. In addition, AAP also has an anticoagulant function due to the structure of uronic acid [25]. The cAAP can be extracted through alkali-soluble alcohol precipitation, and further purified by gel chromatography to get the acid AAP (aAAP). The specific anticoagulant activity of aAAP was $2 \mathrm{IU} / \mathrm{mg}$ when its average mass was $160 \mathrm{kDa}$, and the anticoagulant activity of AAP was mainly contributed by glucuronic acid [26] but not sulfate ester, which is the anticoagulant active ingredient of heparin [27].

Ultrasound-assisted extraction (UAE) uses ultrasound waves with a frequency of 20 to $100 \mathrm{kHz}$. Ultrasound equipment can be divided into an ultrasonic bath (indirect sonification, $45-50 \mathrm{kHz}$ ) and ultrasonic probe (direct sonification, $20 \mathrm{kHz}$ ) [28]. The costs of the equipment are lower than other alternative extraction techniques, and a wide variety of solvents (water, ethyl alcohol, and other organic solvents) can be used $[29,30]$. UAE can notably shorten the extraction time, lower the extraction temperature, through cavitation bubbles, cell disruption, and particle size reduction, and enhance the contact between targeted compounds and solvents [31,32]. Under the above principles, UAE can also reduce the solution viscosity [14], increase the biological functions, and affect the structural composition of the extracted substance [28,33]. Pawlaczyk-Graja et al. [34] compared different methods, including cold extraction, hot extraction, and microwave-assisted extraction (MAE), and UAE. All the methods were carried out in $0.1 \mathrm{M} \mathrm{NaOH}$ and under their respective best parameters to obtain polyphenolic-polysaccharide conjugates with anticoagulant activity from the leaf of Fragariavesca L. UAE gave rise to significant differences in the polysaccharide structures of the conjugates, increased the extraction yield, and the extracts with the highest anticoagulant activity were compared the other two methods aforementioned. Lin et al. [35] reported that the polysaccharides extracted from Ziziphus jujuba Mill var. spinosa seeds had higher antioxidant activity and immunoregulation through UAE than those extracted by heating water extraction (HWE), but the yield was similar, which roughly equated to $0.93 \pm 0.14 \%$ of $6 \mathrm{~h}$ HWE. Yip et al. [36] reported that the yield of polysaccharides was higher, extracted from Ginseng radix and Dendrobii Officinalis Caulis by UAE, compared to boiling water extraction (BWE). The powerful extraction ability and polysaccharide degradation caused by ultrasound collectively contributed to these differences. Optimal extraction was required for the polysaccharides of different sources [36]. In order to explore AAP as functional food ingredients and natural anticoagulants for industrial applications, the UAE method was first optimized to extract crude AAP by using RSM. The crude AAP was further purified, and the chemical structures and anticoagulant activities of AAP obtained were investigated.

\section{Results and Discussion}

\subsection{Single Factor Tests of UAE}

The ultrasound extraction temperature, extraction time, ratio of liquid to raw material, and ultrasonic power are significant parameters that affect the extraction yield of polysaccharides [14,32,37]. The effects of these parameters on the yields of AAP are shown in Figure 1. Briefly, Figure 1A shows that the yield of AAP increased slowly with increasing temperature, eventually reaching a maximum at $70{ }^{\circ} \mathrm{C}$, and then the yield decreased. As the temperature increased, degradation of polysaccharides resulted in a reduction of the surface tension and the viscosity of the solvent [38], increasing the steam pressure in small bubbles, and thus decreasing the ultrasonic cavitation and the mass-transfer intensity [39]. Eventually, the extraction yield dropped. The yields of AAP increased, while the extraction time increased from 10 to $25 \mathrm{~min}$, and the highest extraction yield was reached at $25 \mathrm{~min}$ 
(Figure 1B). However, a longer extraction time induced the degradation of polysaccharides, hence the yield decreased when the extraction time increased continuously [40]. In addition, the yields of AAP were improved as the ratio of liquid to raw material increasing from 30 to $100 \mathrm{~mL} / \mathrm{g}$, reaching the highest yield at $100 \mathrm{~mL} / \mathrm{g}$ (Figure 1C). However, the AAP yields decreased slowly while the ratio of liquid to raw material continued to increase. This might be due to a lower density and viscosity caused by a higher ratio of liquid to raw material, facilitating the dilution of polysaccharides in the solvent [41]. Furthermore, AAP yields were positively related to ultrasound power from 80 to $225 \mathrm{~W}$, whereas the yields were negatively related to the power after $225 \mathrm{~W}$ (Figure 1D). The application of ultrasonic energy produces instantaneous high pressures and temperatures, which promote the formation of cavitation bubbles. Therefore, the solvent more easily destroys the cell wall and enhances the release of the components. However, the excessive sonication energy input exceeds the energy required for cracking, resulting in structural changes and degradation [30]. Finally, the optimal extraction conditions were investigated as $70{ }^{\circ} \mathrm{C}, 25 \mathrm{~min}, 100 \mathrm{~mL} / \mathrm{g}$, and $225 \mathrm{~W}$.
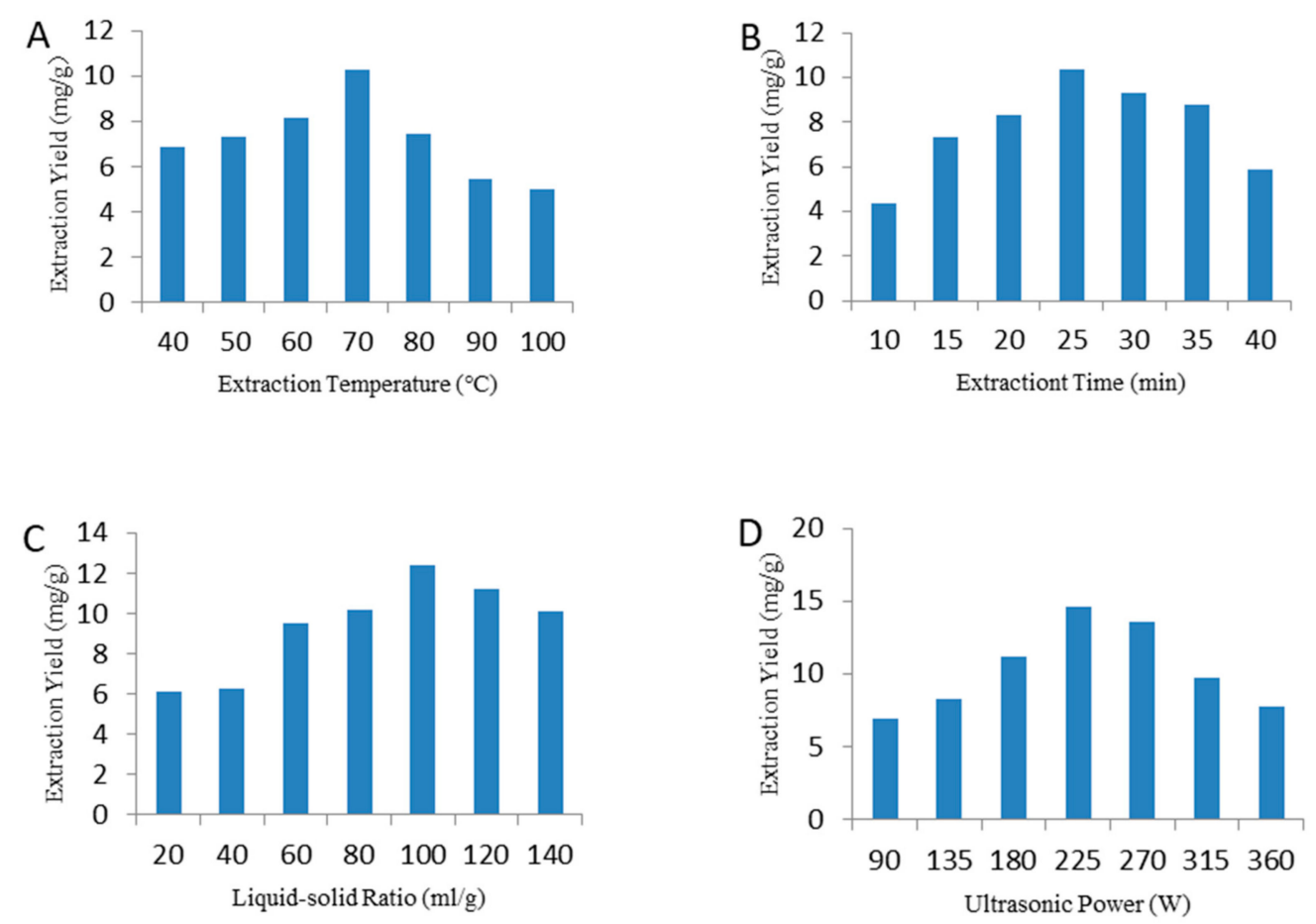

Figure 1. Effects of a different extraction temperature (A), extraction time (B), liquid-solid ratio (C), and ultrasonic power $(\mathbf{D})$ on the extraction yield.

\subsection{Optimization of the Yield of AAP by RSM}

Based on the results of the single factor tests, 29 runs of Box-Behnken experimental design (BBD) were utilized to optimize the UAE conditions. The coded values and the yields of APPs under different extraction conditions are shown in Table 1, and the AAPs yields varied from 9.04 to $16.17 \mathrm{mg} / \mathrm{g}$. All the data were analyzed through multiple regression analysis; a second-order polynomial equation for AAPs yield is represented as Equation (1):

$$
\begin{gathered}
y=15.52+0.40 X_{1}+0.36 X_{2}+0.40 X_{3}+0.18 X_{4}-0.87 X_{1} X_{2}-0.64 X_{1} X_{3}-0.74 X_{1} X_{2} \\
-0.91 X_{2} X_{3}-1.19 X_{2} X_{4}-1.45 X_{3} X_{4}-2.34 X_{1}^{2}-2.05 X_{2}^{2}-2.33 X_{3}^{2}-2.15 X_{4}^{2}
\end{gathered}
$$

where $y$ represents the predicted yield of $\mathrm{AAP}$, and $X_{1}, X_{2}, X_{3}$, and $X_{4}$ are the extraction temperature, extraction time, ratio of liquid to raw material, and ultrasonic power, respectively. 
Table 1. Box-Benhnken design and results of AAP extraction experiments.

\begin{tabular}{|c|c|c|c|c|c|}
\hline \multirow[b]{2}{*}{ No. } & \multicolumn{4}{|c|}{ Codded Variables } & \multirow[b]{2}{*}{$\begin{array}{c}\text { Extraction Yield } \\
\text { of AAP }(\mathrm{mg} / \mathrm{g})\end{array}$} \\
\hline & $\begin{array}{c}X_{1}(\text { Extraction } \\
\left.\text { Temperature, }{ }^{\circ} \mathrm{C}\right)\end{array}$ & $\begin{array}{c}X_{2} \text { (Extraction } \\
\text { Time, min) }\end{array}$ & $\begin{array}{c}X_{3} \\
\text { (Liquid-solid } \\
\text { Ratio, } \mathrm{mL} / \mathrm{g} \text { ) }\end{array}$ & $\begin{array}{c}X_{4} \text { (Ultrasonic } \\
\text { Power, W) }\end{array}$ & \\
\hline 1 & 0 & 0 & -1 & -1 & 9.23 \\
\hline 2 & 0 & 0 & 1 & -1 & 13.02 \\
\hline 3 & 1 & 0 & -1 & 0 & 11.79 \\
\hline 4 & 0 & 0 & 0 & 0 & 15.39 \\
\hline 5 & -1 & -1 & 0 & 0 & 9.59 \\
\hline 6 & 0 & -1 & 0 & 1 & 12.67 \\
\hline 7 & 0 & 1 & 0 & -1 & 12.34 \\
\hline 8 & -1 & 0 & -1 & 0 & 9.32 \\
\hline 9 & 0 & 0 & 0 & 0 & 15.02 \\
\hline 10 & 0 & 0 & 0 & 0 & 16.17 \\
\hline 11 & 0 & 1 & 0 & 1 & 10.69 \\
\hline 12 & 1 & 0 & 1 & 0 & 11.09 \\
\hline 13 & -1 & 0 & 1 & 0 & 11.19 \\
\hline 14 & 1 & 1 & 0 & 0 & 11.32 \\
\hline 15 & 0 & -1 & 0 & -1 & 9.57 \\
\hline 16 & -1 & 1 & 0 & 0 & 11.97 \\
\hline 17 & 0 & -1 & 1 & 0 & 11.76 \\
\hline 18 & -1 & 0 & 0 & -1 & 9.95 \\
\hline 19 & 0 & 0 & 1 & 1 & 10.34 \\
\hline 20 & 0 & -1 & -1 & 0 & 9.04 \\
\hline 21 & 0 & 1 & -1 & 0 & 11.98 \\
\hline 22 & 1 & 0 & 0 & 1 & 10.26 \\
\hline 23 & 0 & 0 & 0 & 0 & 15.13 \\
\hline 24 & 1 & 0 & 0 & -1 & 11.57 \\
\hline 25 & 0 & 0 & -1 & 1 & 12.34 \\
\hline 26 & 0 & 1 & 1 & 0 & 11.07 \\
\hline 27 & 0 & 0 & 0 & 0 & 15.9 \\
\hline 28 & 1 & -1 & 0 & 0 & 12.41 \\
\hline 29 & -1 & 0 & 0 & 1 & 11.59 \\
\hline
\end{tabular}

The analysis of variance (ANOVA) for the fitted quadratic polynomial model of AAP extraction is shown in Table 2. A high model $F$-value $(40.80)$ and a very low $p$-value $(<0.0001)$ indicated that the mode of AAP yield was very significant. Meanwhile, the lack of fit of the $F$-value $(0.71)$ and $p$-value (0.6989) implied that it was insignificant relative to the pure error, which confirmed the goodness-of-fit and suitability of the model for the prediction of the response values under any combination of the independent variables [36].

Table 2. The ANOVA results for the response surface quadratic models of AAP yield.

\begin{tabular}{|c|c|c|c|c|c|}
\hline Source & Sum of Squares & DF & Mean Square & F-Value & $p$-Value \\
\hline Model & 111.82 & 14 & 7.99 & 40.80 & $<0.0001^{* *}$ \\
\hline $\begin{array}{l}X_{1} \text {-extraction } \\
\text { temperature }\end{array}$ & 1.94 & 1 & 1.94 & 9.93 & $0.0071^{* *}$ \\
\hline$X_{2}$-Extraction time & 1.56 & 1 & 1.56 & 7.98 & $0.0135^{*}$ \\
\hline$X_{3}$-liquid-solid ratio & 1.89 & 1 & 1.90 & 9.68 & $0.0076^{* *}$ \\
\hline$X_{4}$-ultrasonic power & 0.41 & 1 & 0.41 & 2.08 & 0.1713 \\
\hline$X_{1} X_{2}$ & 3.01 & 1 & 3.01 & 15.38 & $0.0015^{* *}$ \\
\hline$X_{1} X_{3}$ & 1.65 & 1 & 1.65 & 8.44 & $0.0115^{*}$ \\
\hline$X_{1} X_{4}$ & 2.18 & 1 & 2.18 & 11.12 & $0.0049^{* *}$ \\
\hline$X_{2} X_{3}$ & 3.29 & 1 & 3.29 & 16.83 & $0.0011^{* *}$ \\
\hline$X_{2} X_{4}$ & 5.64 & 1 & 5.64 & 28.81 & $<0.0001^{* *}$ \\
\hline$X_{3} X_{4}$ & 8.38 & 1 & 8.38 & 42.81 & $<0.0001^{* *}$ \\
\hline$X_{1}^{2}$ & 35.59 & 1 & 35.59 & 181.78 & $<0.0001^{* *}$ \\
\hline$X_{2}^{2}$ & 27.19 & 1 & 27.19 & 138.88 & $<0.0001 * *$ \\
\hline$X_{3}^{2}$ & 35.13 & 1 & 35.13 & 179.46 & $<0.0001^{* *}$ \\
\hline$X_{4}^{2}$ & 30.05 & 1 & 30.05 & 153.49 & $<0.0001^{* *}$ \\
\hline Residual & 2.74 & 14 & 0.20 & & \\
\hline Lack of Fit & 1.75 & 10 & 0.18 & 0.71 & 0.6989 \\
\hline Pure Error & 0.99 & 4 & 0.245 & & \\
\hline Cor Total & 114.56 & 28 & & & \\
\hline \multicolumn{6}{|c|}{$R^{2}=0.9761 ;$ Adj $R^{2}=0.9522 ; C V=3.73 \% ;$ Adeq Precision $=20.454$} \\
\hline
\end{tabular}

* Significant difference $(0.01<p<0.05) ;{ }^{* *}$ Extreme significant difference $(p<0.01)$. 
The determination coefficient, $R^{2}(0.9761)$, and the adjusted determination coefficient, $R^{2}(0.9522)$, were reasonably close to 1 . The difference between the two coefficients was within 0.2 , indicating a high degree of correlation between the observed and predicted values [36]. Furthermore, the low values of the coefficient variation $(\mathrm{CV}, 3.73 \%)$ and the high values of adequate precision (15.024) revealed the high degree of precision and reliability of the observed values. The linear coefficients $\left(X_{1}, X_{2}\right.$, and $\left.X_{3}\right)$, interaction coefficients $\left(X_{1} X_{2}, X_{1} X_{3}, X_{1} X_{4}, X_{2} X_{3}, X_{2} X_{4}\right.$, and $\left.X_{3} X_{4}\right)$, and quadratic coefficients $\left(X_{1}^{2}\right.$, $X_{2}{ }^{2}, X_{3}{ }^{2}$, and $X_{4}{ }^{2}$ ) were all significant at the level of $p<0.05$ or $p<0.01$. The other term coefficients were not significant $(p>0.05)$. After removing the insignificant factor, the final empirical model could be described as Equation (2):

$$
\begin{gathered}
y=15.52+0.40 X_{1}+0.36 X_{2}+0.40 X_{3}-0.87 X_{1} X_{2}-0.64 X_{1} X_{3}-0.74 X_{1} X_{2}-0.91 X_{2} X_{3} \\
-1.19 X_{2} X_{4}-1.45 X_{3} X_{4}-2.34 X_{1}^{2}-2.05 X_{2}^{2}-2.33 X_{3}^{2}-2.15 X_{4}^{2} .
\end{gathered}
$$

The predicted values obtained from the model were in agreement with the experimental result (Figure 2A). Meanwhile, the normal probability plots of residuals indicate no serious deviation from normality (Figure 2B) [39].
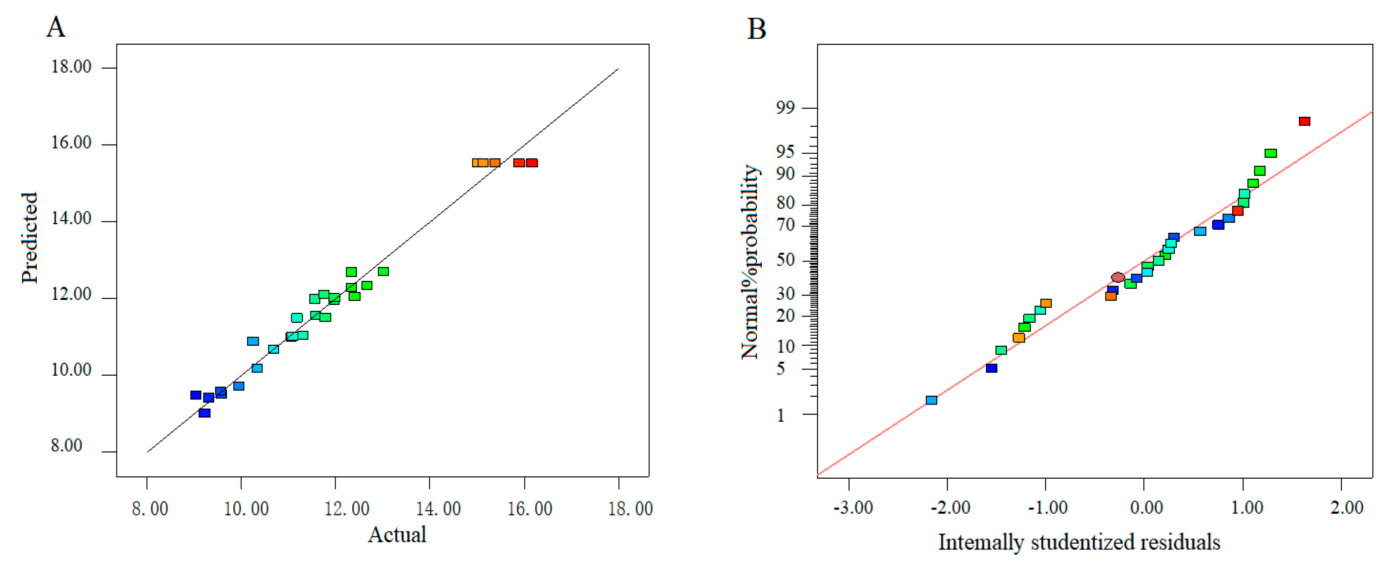

Figure 2. Plots of the adequacy about the proposed model. Plot of the predicted and actual values (A); the normal\% probability plot (B).

The predicted models are presented in contour plots (Figure 3). Figure 3A-F depict that the interactions between any two extraction factors in this experiment were both significant, and the interactions of these factors on the efficiency of AAP extraction were an additive effect $[42,43]$. Furthermore, the model predicted that the maximum yield $(14.74 \mathrm{mg} / \mathrm{g})$ could be obtained by the optimal extraction conditions: Extraction temperature of $74.12^{\circ} \mathrm{C}$; extraction time of $27.28 \mathrm{~min}$; liquid to solid ratio of $102.57 \mathrm{~mL} / \mathrm{g}$; and microwave power of $198.79 \mathrm{~W}$. Considering the practical operability, the operating conditions were: Temperature of $74^{\circ} \mathrm{C}$, time of $28.0 \mathrm{~min}$, ratio of liquid to raw material of $100 \mathrm{~mL} / \mathrm{g}$, and ultrasonic power of $200 \mathrm{~W}$. The actual yield was $14.07 \pm 0.21 \mathrm{mg} / \mathrm{g}(n=3)$, which was similar to the predicted value. Therefore, the model of UAE was accurate and adequate in this study. The AAP was prepared by using the above optimized extraction scheme.

\subsection{Purification and Monosaccharide Composition of aAAP-1}

After the removed protein was concentrated, dialyzed, and lyophilized, the yield ratio of cAAP was about $80.68 \%$. aAAP was precipitated from cAAP with CTAB and purified by using ion exchange chromatography with DEAE Purose 6 Fast Flow column (Figure 4). The yield ratio of aAAP was $62.71 \%$. The yield ratios of aAAP-2 and aAAP-3 were lower than that of aAAP-1 (15.16\%). Only aAAP-1 was further studied. 

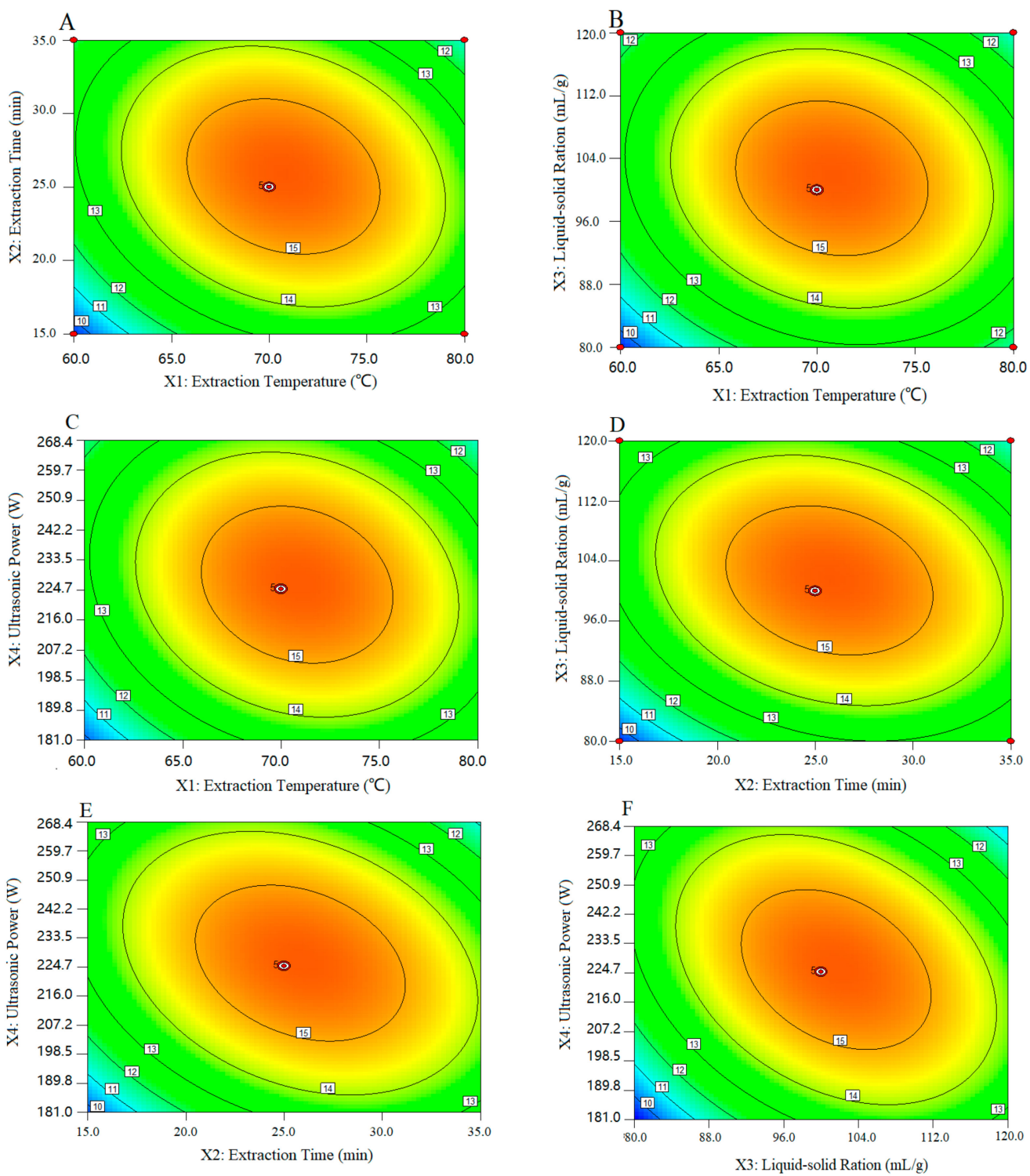

Figure 3. Contour plots showing the significant interactions of the extraction parameters. Extraction temperature and extraction time (A), extraction temperature and liquid-solid ratio (B), extraction temperature and ultrasonic power $(\mathbf{C})$, extraction time and liquid-solid ratio (D), extraction time and ultrasonic power $(\mathbf{E})$, and liquid-solid ratio and ultrasonic power $(\mathbf{F})$.

As shown in Figure 5, aAAP-1 exhibited a single and symmetric peak in the HPLC chromatography, indicating that aAAP-1 was a homogeneous polysaccharide. According to the regression equations $\left(\lg M_{\mathrm{W}}=-0.1973 t+12.456, R^{2}=0.9957 ; \lg M_{\mathrm{n}}=-0.1776 t+11.527, R^{2}=0.9966\right)$, the $M_{\mathrm{W}}$ and $M_{\mathrm{n}}$ of aAAP-1 were 1538 and $1525 \mathrm{Da}$, respectively, with a retention time of $46.98 \mathrm{~min}$, and $M_{\mathrm{w}} / M_{\mathrm{n}}=1.008$, which represented the high homogeneity of aAAP-1.

The HPLC chromatographs of monosaccharide standard and aAAP-1 are shown in Figure 6. These show that aAAP-1 was an acidic heteropolysaccharide mainly composed of Man, GlcUA, Glc, Gal, and Xyl, with molar ratio of 80.63:9.88:2.25:1:31.13. The aldehyde acid of aAAP-1 was glucuronic acid but not galacturonic acid [44], which is consistent with Zhang et al. [45]. The monosaccharide composition and molar ratio of aAAP-1 was different from other polysaccharides extracted from A. auricula-judae [26,46], which indicated that the differences in the extracting conditions, separation, and purification influence the composition of polysaccharides from the same resource. 


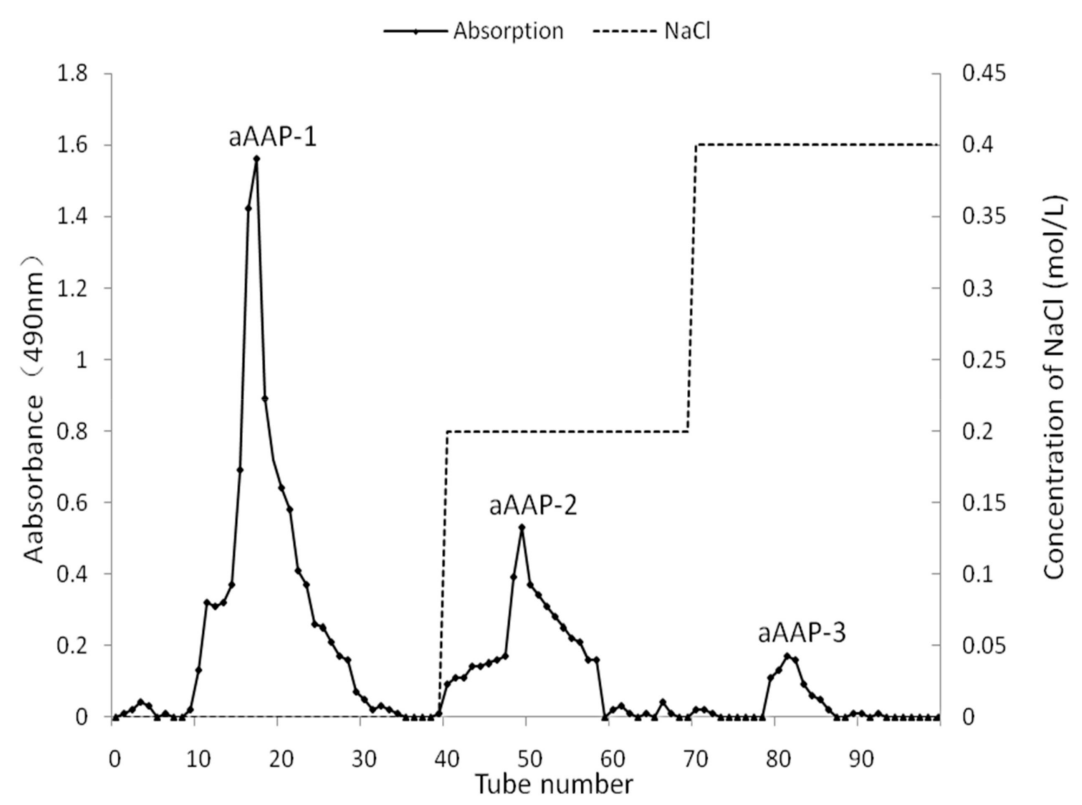

Figure 4. Chromatograms of aAAP-1 separated from cAAPon DEAE Purose 6 Fast Flow.

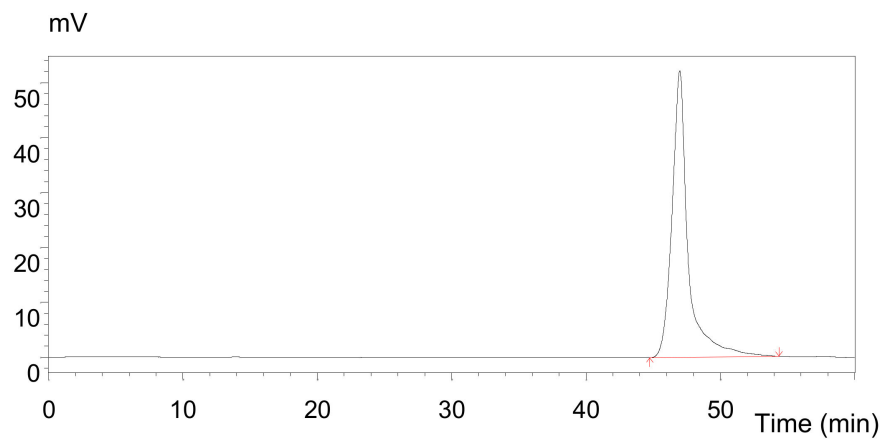

Figure 5. HPLC with tandem gel column profiles of aAAP-1.

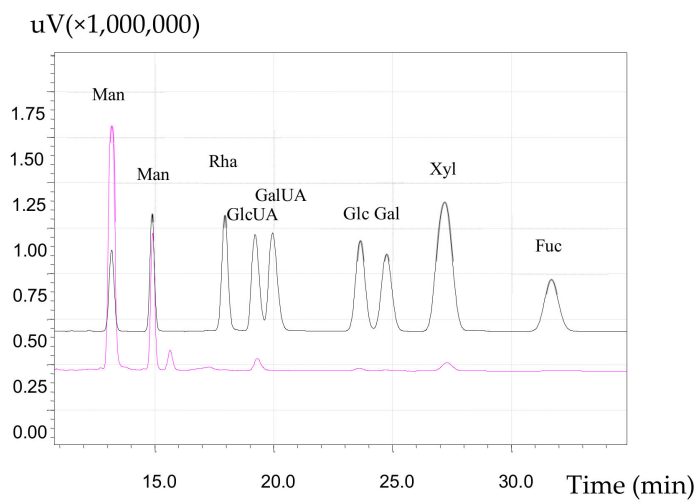

Figure 6. HPLC profiles of aAAP-1 and standard.

\subsection{UV and FT-IR Spectrum of aAAP-1}

The ultraviolet-visible (UV-vis) spectrum of aAAP-1 is shown in Figure 7A, showing only an absorption peak at $200 \mathrm{~nm}$ and without absorption peaks at 260 and $280 \mathrm{~nm}$, indicating that the aAAP-1 did not contain nucleic acids and proteins [47]. The FT-IR spectrum of aAAP-1 was scanned in the range $400-4000 \mathrm{~cm}^{-1}$ and is presented in Figure 7B. A weak peak near $3730 \mathrm{~cm}^{-1}$ indicated a free intermolecular hydroxyl $(-\mathrm{OH})$, the broad and strong absorption peak at $3440 \mathrm{~cm}^{-1}\left(3500-3100 \mathrm{~cm}^{-1}\right)$, which could be assigned to stretching vibrations of intramolecular hydroxyl (-OH) groups [48]. 
The absorption peaks at 2930 and $2850 \mathrm{~cm}^{-1}\left(2800-3000 \mathrm{~cm}^{-1}\right)$ were formed by the chemical bond (C-H) stretch [49], and the peak at $2360 \mathrm{~cm}^{-1}$ was the $\mathrm{C}-\mathrm{H}$ transiting angle [50]. These are typical characteristics of polysaccharides. Uronic acids were evidenced by the strong absorbance band at $1650 \mathrm{~cm}^{-1}(\mathrm{C}-\mathrm{O})$ and two bands at 1480 and $1380 \mathrm{~cm}^{-1}(\mathrm{O}-\mathrm{C}=\mathrm{O})$ [3,51]. In addition, the absorption peaks around $1070 \mathrm{~cm}^{-1}\left(1150-1050 \mathrm{~cm}^{-1}\right)$ were ascribed to $\mathrm{C}-\mathrm{O}-\mathrm{C}$ and $\mathrm{C}-\mathrm{O}-\mathrm{H}$ vibration, indicating the existence of pyranose. The characteristic absorption bands at $841 \mathrm{~cm}^{-1}$ suggested the existence of $\beta$-configurations of saccharide units in aAAP-1 [39]. The $S=O$ stretching is characterized by no absorbance band at $1240 \mathrm{~cm}^{-1}$, proving that aAAp-1 is not a sulfate ester [26].
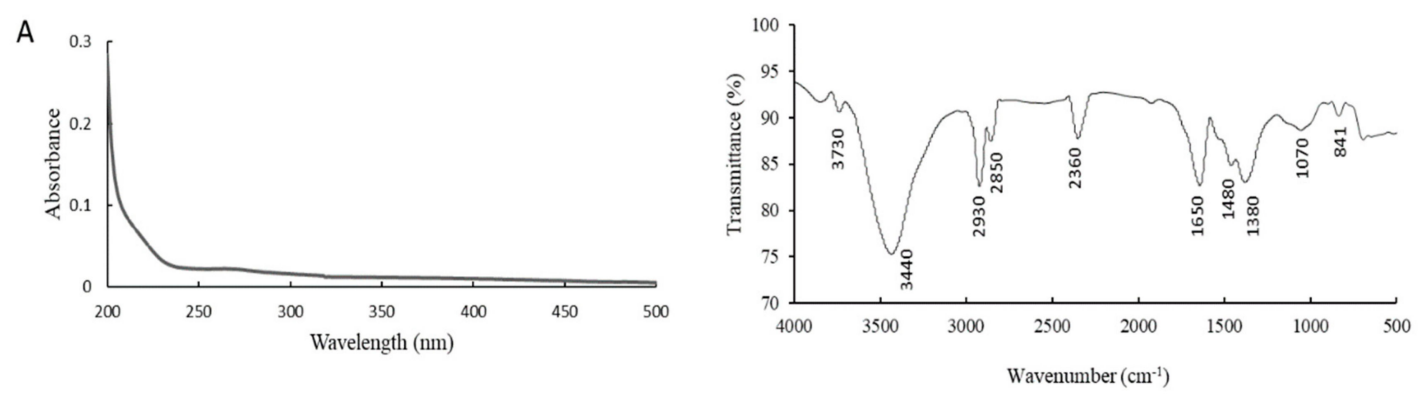

Figure 7. UV (A) and FT-IR (B) spectrum of aAAP-1.

\subsection{Anticoagulant Activity of aAAP-1 In Vitro}

Thrombosis and other blood coagulation with thrombus are caused by a disorder of the balance between the coagulant and anticoagulant system in the body. The activation of the anticoagulation system is an important mechanism for antithrombosis [52]. With a series of enzymatic reactions, the coagulation process in the body can be divided into three stages: Formation of thrombin activator, activation of prothrombin, and transformation of fibrinogen into fibrin. Meanwhile, there are also three accurately controlled anticoagulant systems in the body's blood: 1 . Serine protease inhibitors, such as plasminogen activator inhibitor; 2 . the protein $\mathrm{C} / \mathrm{S} 0$ anticoagulant system; and 3. Surface-binding inhibitor and coagulation inhibitor [53]. Initiated by different mechanisms, the coagulation process can be divided into an exogenous and endogenous coagulation pathway.

The experiments of APTT, PT, and TT were used to test the coagulation time, and estimate the anticoagulant mechanism and pathway. APTT is a test of the endogenous clotting activity. AAAP-1 $(47.3 \mathrm{~s}, 50.0 \mu \mathrm{g} / \mathrm{mL})$ prolonged the clotting time of APTT significantly compared to the saline control $(28.0 \mathrm{~s})$, but it was much lower than that of heparin $(48.7 \mathrm{~s}, 2.0 \mu \mathrm{g} / \mathrm{mL})$. This result is very close to the studies of Li, C. et al. [54] and Lin, S. et al. [55], and represented a deficiency in factors VIII, IX, XI, XII, or Von Willebrand's factor (VWF). AAAP-1 in vitro $(12.5-50 \mu \mathrm{g} / \mathrm{mL})$ could prolong PT (16.1-73.7 s) and TT $(20.3-28.2 \mathrm{~s})$ significantly $(p<0.01)$ compared to the saline control (11.3 and $17.7 \mathrm{~s})$. However, these values were also much lower than those of heparin $(67.9$ and $32.7 \mathrm{~s}, 2.0 \mu \mathrm{g} / \mathrm{mL})$. Additionally, with the increasing dose, PT and TT were lengthened, exhibiting a dose-effect relationship (Table 3). As an important index, TT is mainly a reflection of the degree of the conversion of fibrinogen into fibrin [56]. The clotting time of TT was prolonged significantly, which indicated that aAAP-1 inhibited thrombin activity, and a previous study observed this anticoagulant activity is mostly mediated by the catalysis of thrombin inhibition by antithrombin but not by heparin cofactor II [26]. PT was used to evaluate the overall efficiency of the exogenous clotting pathway. A prolonged PT indicated a deficiency in coagulation factors V, VII, and X. In conclusion, aAAP-1 had a synergic anticoagulant activity by the endogenous and exogenous pathway. Moreover, the anticoagulant activities of aAAP-1 were weaker than those of heparin. 
Table 3. Anticoagulant activity of aAAP-1.

\begin{tabular}{ccccc}
\hline \multirow{2}{*}{ Sample } & \multirow{2}{*}{$\begin{array}{c}\text { Concentration } \\
(\mu \mathrm{g} / \mathbf{m L})\end{array}$} & APTT & PT & TT \\
\cline { 3 - 5 } & & $28.0 \pm 0.3^{\mathrm{b}}$ & $11.3 \pm 0.1$ & $17.7 \pm 0.1$ \\
& 2.0 & $48.7 \pm 0.4$ & $67.9 \pm 0.2$ & $32.7 \pm 0.3$ \\
Control $^{\mathrm{a}}$ & 12.5 & $26.2 \pm 0.3$ & $16.1^{*} \pm 0.2^{* *}$ & $20.3 \pm 0.1^{* *}$ \\
Heparin $^{\mathrm{c}}$ & 25.0 & $27.5 \pm 0.4$ & $26.6 \pm 0.5^{* *}$ & $21.8 \pm 0.1^{* *}$ \\
aAAP-1 $^{* *}$ & 50.0 & $47.3 \pm 1.7^{* *}$ & $73.7 \pm 0.9^{* *}$ & $28.2 \pm 0.2^{* *}$ \\
\hline
\end{tabular}

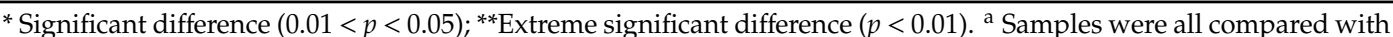
a blank control (saline); ${ }^{b}$ Each clotting time were expressed as means $\pm \mathrm{SD}(\mathrm{n}=3) ;{ }^{\mathrm{c}}$ the 6 th Heparin $(196 \mathrm{IU} / \mathrm{mg})$.

\section{Materials and Methods}

\subsection{Material and Chemicals}

A. auricula-judae was supplied by a forest farm in the Yichun District, Yichun, Heilongjiang Province, China. Standards of Man, Rha, GlcUA, GalUA, Glc, Gal, Xyl, Ara, and Fuc were from Aladdin Chemical Reagent Co., Ltd. (Shanghai, China). Standard dextrans, CTAB, and the standard heparin were all purchased from Sigma-Aldrich Chemical Co. (St. Louis, MO, USA). DEAE Purose 6 Fast Flow was purchased from Jiansu Qianchun Biological Technology Co., Ltd. (Jiangsu, China). APTT, PT, and TT commercial kits were all purchased from Nanjing JianCheng institute of biological engineering (Nanjing, China). Normal plasma and all other reagents and chemicals used were of analytical grade.

\subsection{Extraction and Purification of Acidic Polysaccharides from A. auricula-judae}

\subsubsection{Ultrasound-Assisted Extraction (UAE) of AAP}

UAE was performed based on a previously reported method with some modifications [39]. Both the designs of the single-factor experiment and Box-Behnken experimental (BBD) were also applied for the optimization of the UAE conditions. Briefly, after being dried to a constant weight at $70{ }^{\circ} \mathrm{C}$, A. auricula-judae was ground to a particle diameter size of $20-50 \mu \mathrm{m}$ and defatted by extracting with ethyl acetate and methanol. The removal of some colored materials was achied with a treatment with $95 \% \mathrm{EtOH}$ following [57]. The extracted residue was extracted with sodium hydroxide solution $(0.01 \mathrm{M})$ by continuous UAE (HX-900 ET, Shanghai Huxi Industrial co. LTD, Shanghai, China). The effects of different extraction temperatures $\left(40,50,60,70,80,90\right.$, and $\left.100^{\circ} \mathrm{C}\right)$, different extraction times $(10$, $15,20,25,30,35$, and $10 \mathrm{~min})$, and the liquid-solid ratio $(20,40,60,80,100,120$, and $140 \mathrm{~mL} / \mathrm{g}$ ), on the yields of AAP $(\mathrm{mg} / \mathrm{g})$ were investigated by using a single-factor experimental design. While the ultrasound power were set as $225 \mathrm{~W}$, the extraction time and the liquid-solid ratio were set as $25 \mathrm{~min}$ and $100 \mathrm{~mL} / \mathrm{g}$ ), the extraction temperature and the liquid-solid ratio were set as $70{ }^{\circ} \mathrm{C}$ and $100 \mathrm{~mL} / \mathrm{g}$, and the extraction temperature and the extraction time were set as $70^{\circ} \mathrm{C}$ and $25 \mathrm{~min}$.

A three-level BBD was applied to further optimize the UAE conditions. The extraction temperature $\left(X_{1},{ }^{\circ} \mathrm{C}\right)$, extraction time $\left(X_{2}, \mathrm{~min}\right)$, liquid-solid ratio $\left(X_{3}, \mathrm{~mL} / \mathrm{g}\right)$, and ultrasound power $\left(X_{4}, \mathrm{~W}\right)$ were preferred for the independent variables. The variables and their levels are presented in Table 4.

Table 4. Independent variables and levels in BBD.

\begin{tabular}{ccccc}
\hline Independent Variables & Symbol & $\mathbf{- 1}$ & Level & $\mathbf{1}$ \\
\hline Extraction temperature $\left({ }^{\circ} \mathrm{C}\right)$ & $X_{1}$ & 60 & 70 & 80 \\
Extraction time $(\mathrm{min})$ & $X_{2}$ & 20 & 25 & 30 \\
Liquid-solid ratio $(\mathrm{mL} / \mathrm{g})$ & $X_{3}$ & 80 & 100 & 120 \\
Ultrasonic power $(\mathrm{W})$ & $X_{4}$ & 180 & 225 & 270 \\
\hline
\end{tabular}


The $\mathrm{NaOH}$ solution of polysaccharides was neutralized with $0.4 \mathrm{M} \mathrm{HCl}$, the solids were separated by centrifugation $(4000 \mathrm{rpm}, 5 \mathrm{~min}$ ), and the polysaccharides were precipitated from the supernatant by an excess of ethanol $(4: 1, v / v)$ precipitation. Then, flowed deproteinization and dialysis (3.5 kDa) was performed, the output was freeze-dried, and the crude cAAP was obtained [10].

\subsubsection{Isolation and Purification of aAAP}

Using twice the volume of cAAP $(10 \mathrm{mg} / \mathrm{mL})$, water solution was mixed with CTAB (5\%) water solution for $4 \mathrm{~h}$. The precipitation was aAAP separated by centrifugation [58]. aAAP (400 mg) was dissolved in $2 \mathrm{~mL}$ of distilled water, and filtrated with a syringe filter $(0.22 \mu \mathrm{m})$. The solution was applied to an anion exchange column DEAE Purose 6 Fast Flow $(\Phi \times h, 2.6 \times 20 \mathrm{~cm})$ and sequentially eluted using $0.0,0.2$, and $0.4 \mathrm{M} \mathrm{NaCl}$ aqueous solution with a flow rate of $1 \mathrm{~mL} / \mathrm{min}$. The elution of the polysaccharides was $10 \mathrm{~mL}$ per tube and monitored at $490 \mathrm{~nm}$ by using the phenol-sulfuric acid method [59]. The eluate of the same fraction was pooled, concentrated, dialyzed (3.5 kDa), and lyophilized.

\subsection{Determination of the Molecular Weight and Monosaccharide Composition Analysis}

The molecular weight $\left(M_{\mathrm{w}}, M_{\mathrm{n}}\right)$ of aAAP-1 was measured by using Shimadzu LC-10AVP HPLC system (Shimadzu Corporation, Kyoto, Japan), equipped with BRT 105-104-102 Tandem gel column $(\Phi \times$ h, $8.0 \mathrm{~mm} \times 300 \mathrm{~mm}$, Borui Saccharide, Biotech. Co. Ltd., YangZhou, China) and a Parallax detector. After being centrifuged $(12000 \mathrm{rpm}, 10 \mathrm{~min})$ and filtered with a $0.45-\mu \mathrm{m}$ filter, the $(5.0 \mathrm{mg} / \mathrm{mL})$ supernatant was injected into the detector. The $0.05 \mathrm{M} \mathrm{NaCl}$ was regarded as the flow phase, and the elution rate was $0.6 \mathrm{~mL} / \mathrm{min}$. The standard curve, where the elution time was plotted against the logarithm of the molecular weight, was made using dextran as a standard $(1152,11,600,23,800,48,600$, 80,900, 148,000, 273,000, and 409,800 kDa).

Monosaccharide composition analysis of aAAP-1 was performed using a Shimadzu LC-10A HPLC system (Shimadzu Corporation, Tokyo, Japan) with an Agilent eclipse plus C18 column $(\Phi \times \mathrm{h}, 4.5 \mathrm{~mm}$ $\times 150 \mathrm{~mm}, 5 \mu \mathrm{m}$, Agilent Technologies Inc., Santa Clara, CA, USA). The detection wavelength was set at $254 \mathrm{~nm}$. The temperature of the column was maintained at $35^{\circ} \mathrm{C}$. The mobile phase consisted of acetonitrile (A) and $\mathrm{NaH}_{2} \mathrm{PO}_{4}$ buffer (B: $0.45 \mathrm{~g} \mathrm{NaH} \mathrm{PO}_{4}+900 \mathrm{~mL}$ purified water $+1.0 \mathrm{~mL} \mathrm{TEA}+$ $100 \mathrm{~mL}$ acetonitrile) with a flow rate of $1.0 \mathrm{~mL} / \mathrm{min}$. A gradient program was conducted by $94 \% \mathrm{~B}+6 \%$ $\mathrm{A}(V: V), 4 \mathrm{~min}$ and $88 \% \mathrm{~B}+12 \% \mathrm{~A}(V: V), 55 \mathrm{~min}$.

\subsection{UV and FT-IR Analysis}

AAAP-1 was dissolved in distilled water and scanned on a Perkin Elmer Lambda750 UV-vis spectrophotometer (Waltham, MA, USA) in the wavelength range from 200 to $500 \mathrm{~nm}$. FT-IR spectra of -1 were recorded using a Fourier transform infrared (FT-IR) 8400 S spectrometer (Shimadzu Corporation, Tokyo, Japan) by mixing the sample (2 mg) with KBr powder $(100 \mathrm{mg})$ and pressing it into a disk (10 mm diameter). The FT-IR spectrum of aAAP-1 was recorded in the frequency range 400 to $4000 \mathrm{~cm}^{-1}$.

\subsection{Blood Coagulation Assays}

Normal human plasma was prepared from healthy donors without a history of bleeding or thrombosis. The preparation of plasma followed previous methods [12]. aAAP-1 of different concentrations $(50,25,12.5 \mu \mathrm{g} / \mathrm{mL})$ was mixed with plasma (sample: plasma=1: $4(v / v)$ ), followed by incubation at $37^{\circ} \mathrm{C}$ for $5 \mathrm{~min}$, and then the clotting times were recorded in a CA7000 automatic coagulation analyzer (Sysmex Corporation, Kobe, Japan). The samples, including the positive control of heparin $(2 \mu \mathrm{g} / \mathrm{mL})$, were dissolved in saline, and a control group of saline only was used. 


\subsection{Statistical Analysis}

All experiments were conducted in triplicate, and data were expressed in means \pm standard deviations. The obtained data were analyzed by the statistical package of the Design Expert software 8.0.5 (Stat-Ease Inc., Minneapolis, MN, USA). The independent sample t-test $(p<0.05)$ was used to explore significant differences.

\section{Conclusions}

In this study, the optimal extraction conditions for the extraction of Auricularia auricula-judae polysaccharides (AAP) were obtained by using response surface methodology. Furthermore, the aAAP was precipitated from AAP with CTAB, and purified through the DEAE Purose 6 Fast Flow to obtain aAAP-1. The aAAP-1 was acidic polysaccharide with glucuronide and had a synergic anticoagulant activity by the endogenous and exogenous pathway. The senior structure of aAAP-1 needs to be investigated in future work, which will reveal the relationship of the structure-anticoagulant function. AAP should be further explored by using different extraction and purification methods to improve the utilization as a functional food ingredient in antithrombotic health foods, which will have broad market prospects in daily health care and post-disease recovery.

Author Contributions: Z.W. and J.S. conceived and designed the experiments; C.B. designed and performed the experiments, analyzed the data; wrote the initial draft; and revised the manuscript. All authors have read and agreed to the published version of the manuscript.

Funding: This research was funded by NATIONAL NATURAL SCIENCE FOUNDATION OF CHINA, grant number 31801485 .

Acknowledgments: Authors want to thank Lan Yang Ji for providing raw material of A. auricula-judae, and ChangRui Xing for technical support.

Conflicts of Interest: The authors declare no conflict of interest.

\section{References}

1. Yu, Y.; Shen, M.; Song, Q.; Xie, J. Biological activities and pharmaceutical applications of polysaccharide from natural resources: A review. Carbohydr. Polym. 2018, 183, 91-101. [CrossRef] [PubMed]

2. Lopez, A.D.; Murray, C.C. The global burden of disease, 1990-2020. Nat. Med. 1998, 4, 1241-1243. [CrossRef] [PubMed]

3. Sayari, N.; Balti, R.; Mansour, M.B.; Amor, I.B.; Graiet, I.; Gargouri, J.; Bougatef, A. Anticoagulant properties and cytotoxic effect against HCT116 human colon cell line of sulfated glycosaminoglycans isolated from the Norway lobster (Nephrops norvegicus) shell. Biomed. Pharmacother. 2016, 80, 322-330. [CrossRef] [PubMed]

4. Ghlissi, Z.; Krichen, F.; Kallel, R.; Amor, I.B.; Boudawara, T.; Gargouri, J.; Sahnoun, Z. Sulfated polysaccharide isolated from Globularia alypum L.: Structural characterization, in vivo and in vitro anticoagulant activity, and toxicological profile. Int. J. Biol. Macromol. 2019, 123, 335-342. [CrossRef] [PubMed]

5. Fu, L.; Suflita, M.; Linhardt, R.J. Bioengineered heparins and heparan sulfates. Adv. Drug. Deliv Rev. 2016, 97, 237-249. [CrossRef] [PubMed]

6. Albuquerque, I.R.L.; Queiroz, K.C.S.; Alves, L.G.; Santos, E.A.D.; Leite, E.L.; Rocha, H.A.O. Heterofucans from Dictyota menstrualis have anticoagulant activity. Braz. J. Med. Biol. Res. 2004, 37, 167-171. [CrossRef] [PubMed]

7. Song, S.; Wang, L.; Wang, L.; Yu, Q.; Ai, C.; Fu, Y.; Zhu, Z. Structural characterization and anticoagulant activity of two polysaccharides from Patinopecten yessoensis viscera. Int. J. Biol. Macromol. 2019, 136, 579-585. [CrossRef]

8. Sun, F.; Liu, Y.; Wang, D.; Wang, Z.; Mu, H.; Wang, F.; Duan, J. A novel photocleavable heparin derivative with light controllable anticoagulant activity. Carbohydr. Polym. 2018, 184, 191-198. [CrossRef]

9. Guan, R.; Peng, Y.; Zhou, L.; Zheng, W.; Liu, X.; Wang, P.; Zhao, J. Precise structure and anticoagulant activity of fucosylated glycosaminoglycan from Apostichopus japonicus: Analysis of its depolymerized fragments. Mar. Drugs 2019, 17, 195. [CrossRef] 
10. Wang, L.; Zhang, X.; Niu, Y.; Ahmed, A.F.; Wang, J.; Kang, W. Anticoagulant activity of two novel polysaccharides from flowers of Apocynum venetum L. Int. J. Biol. Macromol. 2019, 124, 1230-1237. [CrossRef]

11. Ullah, S.; Khalil, A.A.; Shaukat, F.; Song, Y. Sources, extraction and biomedical properties of polysaccharides. Foods 2019, 8, 304. [CrossRef] [PubMed]

12. Cai, W.; Xie, L.; Chen, Y.; Zhang, H. Purification, characterization and anticoagulant activity of the polysaccharides from green tea. Carbohydr. Polym. 2013, 92, 1086-1090. [CrossRef] [PubMed]

13. Sun, S.; Zhang, X.; Chen, W.; Zhang, L.; Zhu, H. Production of natural edible melanin by Auricularia auricula and its physicochemical properties. Food Chem. 2016, 196, 486-492. [CrossRef] [PubMed]

14. Wang, Y.; Wang, C.; Guo, M. Effects of ultrasound treatment on extraction and rheological properties of polysaccharides from Auricularia Cornea var. Li. Molecules 2019, 24, 939. [CrossRef]

15. Xu, Y.; Shen, M.; Chen, Y.; Lou, Y.; Luo, R.; Chen, J.; Zhang, Y.; Li, J.; Wang, W. Optimization of the polysaccharide hydrolysate from Auricularia auricula with antioxidant activity by response surface methodology. Int. J. Biol. Macromol. 2018, 113, 543-549. [CrossRef]

16. Su, Y.; Li, L. Structural characterization and antioxidant activity of polysaccharide from four auriculariales. Carbohydr. Polym. 2020, 229, 115407. [CrossRef]

17. Basso, A.M.M.; De Castro, R.J.A.; de Castro, T.B.; Guimarães, H.I.; Polez, V.L.P.; Carbonero, E.R.; Bocca, A.L. Immunomodulatory activity of $\beta$-glucan-containing exopolysaccharides from Auricularia auricular in phagocytes and mice infected with Cryptococcus neoformans. Medical. Mycol. 2019, 58, 227-239. [CrossRef]

18. Lu, A.; Shen, M.; Fang, Z.; Xu, Y.; Yu, M.; Wang, S.; Wang, W. Antidiabetic Effects of the Auricularia auricular polysaccharides simulated hydrolysates in experimental type-2 diabetic rats. Nat. Prod. Commun. 2018, 13, 195-200. [CrossRef]

19. Chen, Z.; Wang, J.; Fan, Z.; Qiu, J.; Rumbani, M.; Yang, X.; Wang, Z. Effects of polysaccharide from the fruiting bodies of Auricularia auricular on glucose metabolism in 60Co- $\gamma$-radiated mice. Int. J. Biol. Macromol. 2019, 135, 887-897. [CrossRef]

20. Ma, Z.; Wang, J.; Zhang, L.; Zhang, Y.; Ding, K. Evaluation of water soluble $\beta$-D-glucan from Auricularia auricular-judae as potential anti-tumor agent. Carbohydr. Polym. 2010, 80, 977-983. [CrossRef]

21. Ma, Y.; Wang, C.; Zhang, Q.; Peng, X.; Feng, Y.; Meng, X. The effects of polysaccharides from Auricularia auricula (Huaier) in adjuvant anti-gastrointestinal cancer therapy: A systematic review and network meta-analysis. Pharmacol. Res. 2018, 132, 80-89. [CrossRef] [PubMed]

22. Chang, A.K.T.; Frias, R.R., Jr.; Alvarez, L.V.; Bigol, U.G.; Guzman, J.P.M.D. Comparative antibacterial activity of commercial chitosan and chitosan extracted from Auricularia sp. Biocatal. Agric. Biotechnol. 2019, 17, 189-195. [CrossRef]

23. Linnakoski, R.; Reshamwala, D.; Veteli, P.; Cortina-Escribano, M.; Vanhanen, H.; Marjomäki, V. Antiviral agents from fungi: Diversity, mechanisms and potential applications. Front. Microbiol. 2018, 9, 2325. [CrossRef] [PubMed]

24. Cheung, P.C. The hypocholesterolemic effect of two edible mushrooms: Auricularia auricula (tree-ear) and Tremella fuciformis (white jelly-leaf) in hypercholesterolemic rats1. Nutr. Res. 1996, 16, 1721-1725. [CrossRef]

25. Ma, F.; Wu, J.; Li, P.; Tao, D.; Zhao, H.; Zhang, B.; Li, B. Effect of solution plasma process with hydrogen peroxide on the degradation of water-soluble polysaccharide from Auricularia auricula. II: Solution conformation and antioxidant activities in vitro. Carbohydr. Polym. 2018, 198, 575-580. [CrossRef]

26. Yoon, S.J.; Yu, M.A.; Pyun, Y.R.; Hwang, J.K.; Chu, D.C.; Juneja, L.R.; Mourao, P.A. The nontoxic mushroom Auricularia auricula contains a polysaccharide with anticoagulant activity mediated by antithrombin. Thromb. Res. 2003, 112, 151-158. [CrossRef]

27. Cifonelli, J.A. The relationship of molecular weight, and sulfate content and distribution to anticoagulant activity of heparin preparations. Carbohydr. Res. 1974, 37, 145-154. [CrossRef]

28. Cikoš, A.M.; Jokić, S.; Šubarić, D.; Jerković, I. Overview on the application of modern methods for the extraction of bioactive compounds from marine macroalgae. Mar. Drugs. 2018, 16, 348. [CrossRef]

29. Kadam, S.U.; Tiwari, B.K.; O’Donnell, C.P. Application of novel extraction technologies for extraction of bioactives from marine algae. J. Agric. Food. Chem. 2013, 61, 4667-4675. [CrossRef]

30. Wang, J.; Zhang, M.; Fang, Z. Recent development in efficient processing technology for edible algae: A review. Trends. Food. Sci. Technol. 2019, 88, 251-259. [CrossRef] 
31. Kia, A.G.; Ganjloo, A.; Bimakr, M. A short extraction time of polysaccharides from fenugreek (Trigonella foencem graecum) seed using continuous ultrasound acoustic cavitation: Process optimization, characterization and biological activities. Food. Bioprocess. Technol. 2018, 11, 2204-2216. [CrossRef]

32. Vilkhu, K.; Mawson, R.; Simons, L.; Bates, D. Applications and opportunities for ultrasound assisted extraction in the food industry-A review. Innov. Food. Sci. Emerg. Technol. 2008, 9, 161-169. [CrossRef]

33. Mena-García, A.; Ruiz-Matute, A.I.; Soria, A.C.; Sanz, M.L. Green techniques for extraction of bioactive carbohydrates. TrAC Trend. Anal. Chem. 2019, 119, 115612-115621. [CrossRef]

34. Pawlaczyk-Graja, I.; Balicki, S.; Wilk, K.A. Effect of various extraction methods on the structure of polyphenolic-polysaccharide conjugates from Fragaria vesca L. leaf. Int. J. Biol. Macromol. 2019, 130, 664-674. [CrossRef] [PubMed]

35. Lin, T.; Liu, Y.; Lai, C.; Yang, T.; Xie, J.; Zhang, Y. The effect of ultrasound assisted extraction on structural composition, antioxidant activity and immunoregulation of polysaccharides from Ziziphus jujuba Mill var. spinosa seeds. Ind. Crop. Prod. 2018, 125, 150-159. [CrossRef]

36. Yip, K.M.; Xu, J.; Tong, W.S.; Zhou, S.S.; Yi, T.; Zhao, Z.Z.; Chen, H.B. Ultrasound-assisted extraction may not be a better alternative approach than conventional boiling for extracting polysaccharides from herbal medicines. Molecules 2016, 21, 1569. [CrossRef] [PubMed]

37. Babamoradi, N.; Yousefi, S.; Ziarati, P. Optimization of ultrasound-assisted extraction of functional polysaccharides from common mullein (Verbascum thapsus L.) flowers. J. Food Process. Eng. 2018, 41, e12851. [CrossRef]

38. Bradley, T.D.; Mitchell, J.R. The determination of the kinetics of polysaccharide thermal degradation using high temperature viscosity measurements. Carbohydr. Polym. 1988, 9, 257-267. [CrossRef]

39. Wang, L.; Cheng, L.; Liu, F.; Li, T.; Yu, Z.; Xu, Y.; Yang, Y. Optimization of ultrasound-assisted extraction and structural characterization of the polysaccharide from pumpkin (Cucurbita moschata) seeds. Molecules 2018, 23, 1207. [CrossRef]

40. Wang, J.; Lu, H.D.; Muhammad, U.; Han, J.Z.; Wei, Z.H.; Lu, Z.X.; Lu, F.X. Ultrasound-assisted extraction of polysaccharides from Artemisia selengensis Turcz and its antioxidant and anticancer activities. J. Food. Sci. Technol. 2016, 53, 1025-1034. [CrossRef] [PubMed]

41. Guo, H.; Yuan, Q.; Fu, Y.; Liu, W.; Su, Y.H.; Liu, H.; Wu, C.Y.; Zhao, L.; Zhang, Q.; Lin, D.R.; et al. Extraction optimization and effects of extraction methods on the chemical structures and antioxidant activities of polysaccharides from Snow Chrysanthemum (Coreopsis Tinctoria). Polymers 2019, 11, 215. [CrossRef] [PubMed]

42. Jooyandeh, H.; Noshad, M.; Khamirian, R.A. Modeling of ultrasound-assisted extraction, characterization and in vitro pharmacological potential of polysaccharides from Vaccinium arctostaphylos L. Int. J. Biol. Macromol. 2018, 107, 938-948. [CrossRef] [PubMed]

43. Wu, D.T.; Liu, W.; Han, Q.H.; Wang, P.; Xiang, X.R.; Ding, Y.; Qin, W. Extraction optimization, structural characterization, and antioxidant activities of polysaccharides from Cassia Seed (Cassia obtusifolia). Molecules 2019, 24, 2817. [CrossRef] [PubMed]

44. Chen, G.; Luo, Y.C.; Ji, B.P.; Li, B.; Guo, Y.; Li, Y.; Xiao, Z.L. Effect of polysaccharide from Auricularia auricula on blood lipid metabolism and lipoprotein lipase activity of ICR mice fed a cholesterol-enriched diet. J. Food Sci. 2008, 73, H103-H108. [CrossRef]

45. Zhang, L.; Yang, L.; Ding, Q.; Chen, X. Studies on molecular weights of polysaccharides of Auricularia auricula-judae. Carbohydr. Res. 1995, 270, 1-10. [CrossRef]

46. Wu, Q.; Tan, Z.; Liu, H.; Gao, L.; Wu, S.; Luo, J.; Zhang, W.; Zhao, T.; Yu, J.; Xu, X. Chemical characterization of Auricularia auricula polysaccharides and its pharmacological effect on heart antioxidant enzyme activities and left ventricular function in aged mice. Int. J. Biol. Macromol. 2010, 46, 284-288. [CrossRef]

47. Chen, Y.; Zhang, J.; Li, Q.; Wu, J.; Sun, F.; Liu, Z.; Liang, S. Response surface methodology for optimizing the ultrasound-assisted extraction of polysaccharides from Acanthopanax giraldii. Chem. Pharm. Bull. 2018, 66, 785-793. [CrossRef]

48. Li, E.; Yang, S.; Zou, Y.; Cheng, W.; Li, B.; Hu, T.; Pang, D. Purification, characterization, prebiotic preparations and antioxidant activity of oligosaccharides from mulberries. Molecules 2019, 24, 2329. [CrossRef]

49. Kizil, R.; Irudayaraj, J.; Seetharaman, K. Characterization of irradiated starches by using FT-Raman and FTIR spectroscopy. J. Agric. Food Chem. 2002, 50, 3912-3918. [CrossRef] 
50. Ying, Z.; Han, X.; Li, J. Ultrasound-assisted extraction of polysaccharides from mulberry leaves. Food. Chem. 2011, 127, 1273-1279. [CrossRef]

51. Chen, X.; Song, L.; Wang, H.; Liu, S.; Yu, H.; Wang, X.; Li, P. Partial characterization, the immune modulation and anticancer activities of sulfated polysaccharides from filamentous microalgae Tribonema sp. Molecules 2019, 24, 322. [CrossRef] [PubMed]

52. Zong, S.; Ji, J.; Li, J.; Yang, Q.H.; Ye, M. Physicochemical properties and anticoagulant activity of polyphenols derived from Lachnum singerianum. J.Food Drug Anal. 2017, 25, 837-844. [CrossRef] [PubMed]

53. Corrigan, J.J., Jr.; Ray, W.L.; May, N. Changes in the blood coagulation system associated with septicemia. New Engl. J. Med. 1968, 279, 851-856. [CrossRef] [PubMed]

54. Li, C.; Mao, X.; Xu, B. Pulsed Electric Field Extraction Enhanced Anti-coagulant effect of fungal polysaccharide from Jew's Ear (Auricularia auricula). Phytochem. Analysis 2012, 24, 36-40. [CrossRef] [PubMed]

55. Lin, S.; Majida, A.W.; Niu, L.; Zhou, F.; Zhang, Y.; Wang, M.; Wang, L. Degradation enhances the anticoagulant and antiplatelet activities of polysaccharides from Lycium barbarum L. leaves. Int. J. Biol. Macromol. 2019, 133, 674-682. [CrossRef] [PubMed]

56. Xie, P.; Zhang, Y.; Wang, X.; Wei, J.; Kang, W. Antithrombotic effect and mechanism of Rubus spp. Blackberry. Food. Funct. 2017, 8, 2000-2012. [CrossRef]

57. Zhang, H.; Wang, Z.Y.; Zhang, Z.; Wang, X. Purified Auricularia auricular-judae polysaccharide (AAP Ia) prevents oxidative stress in an ageing mouse model. Carbohydr. Polym. 2011, 84, 638-648. [CrossRef]

58. Phélippé, M.; Gonçalves, O.; Thouand, G.; Cogne, G.; Laroche, C. Characterization of the polysaccharides chemical diversity of the cyanobacteria Arthrospira platensis. Algal. Res. 2019, 38, 101426.

59. Dubois, M.; Gilles, K.A.; Hamilton, J.K.; Rebers, P.T.; Smith, F. Colorimetric method for determination of sugars and related substances. Anal. Chem. 1956, 28, 350-356. [CrossRef]

Sample Availability: Samples of the compounds cAAP are available from the authors.

(C) 2020 by the authors. Licensee MDPI, Basel, Switzerland. This article is an open access article distributed under the terms and conditions of the Creative Commons Attribution (CC BY) license (http://creativecommons.org/licenses/by/4.0/). 